\title{
On the warm inflow at the eastern boundary of the Weddell Gyre
}

\author{
S. Ryan ${ }^{\mathrm{a}, *}$, M. Schröder ${ }^{\mathrm{a}}$, O. Huhn ${ }^{\mathrm{b}}$, R. Timmermann ${ }^{\mathrm{a}}$ \\ a Alfred Wegener Institute, Bussestrasse 24 D-27570 Bremerhaven, Germany \\ ${ }^{\mathrm{b}}$ Institute of Environmental Physics (IUP), University of Bremen, Germany
}

\section{A R T I C L E I N F O}

Available online 2 December 2015

Keywords:

Eastern boundary

Weddell Gyre

Warm Deep Water

Circumpolar Deep Water

Greenwich Meridian

Optimum Multiparameter Analysis

\begin{abstract}
A B S T R A C T
The Weddell Sea plays an important role for the global oceans and climate by being one of the biggest production and export areas of Antarctic Bottom Water (AABW). Circumpolar Deep Water (CDW) enters the Weddell Gyre (WG) at its eastern boundary. Then called Warm Deep Water (WDW), it is a major contributor to the formation of deep and bottom waters due to ocean-ice shelf interactions in the southern and soutwestern Weddell Sea. Hydrographic data collected between 0 and $30^{\circ} \mathrm{E}$ on the $R V$ Polarstern cruise ANT XX/2 reveals a two-core structure for the eastern inflow of warm water at roughly $20^{\circ} \mathrm{E}$ but not further downstream at the Greenwich meridian (GM). Model results and climatological fields suggest that the two cores represent two separate modes of warm inflow. One mode is driven by eddy mixing in the northeastern corner of the WG and the other one is an advective mode, forming the southern branch of the inflow which extends beyond $30^{\circ} \mathrm{E}$ before turning westward. Both pathways are likely to carry waters from different origins within the Antarctic Circumpolar Current ACC, where more ventilated CDW is found at the Southern Boundary SB compared to the centre. The southern route shows considerable interannual variability in the model. A variable inflow of two types of CDW together with admixed recirculated and cooler waters from the Weddell Sea can potentially contribute to the observed variability and warming trend of WDW over the last decade at the GM.
\end{abstract}

(c) 2015 Elsevier Ltd. All rights reserved.

\section{Introduction}

The oceanic meridional overturning circulation plays an important role in the global climate system by transporting heat, salt, and other properties around the globe. The Weddell Sea contributes to this circulation by producing and exporting Antarctic Bottom Water (AABW) (Carmack, 1977; Orsi et al., 1999), which is the coldest and most voluminous water mass in the world oceans. Johnson (2008) suggests that the total volume of AABW is about twice as much as that of the North Atlantic Deep Water (NADW). Although many studies in the past have revised the contribution of

Abbreviations: AABW, Antarctic Bottom Water; ACC, Antarctic Circumpolar Current; ADCP, Acoustic Doppler Current Profiler; BRIOS, Bremerhaven Regional Ice Ocean Simulations; CARS, CSIRO Atlas of Regional Seas; CDW, Circumpolar Deep Water; CFC, Chlorofluorocarbon; GM, Greenwich meridian; HSSW, High Salinity Shelf Water; LCDW, Lower Circumpolar Deep Water; mWDW, modified Warm Deep Water; NADW, North Atlantic Deep Water; NCEP, National Centers for Environmental Prediction; OMP, Optimum Multiparameter; PF, Polar Front; SACCF, Southern ACC Front; SAM, Southern Annular Mode; SB, Southern Boundary; SWT, Source Water Types; UCDW, Upper Circumpolar Deep Water; WDW, Warm Deep Water; WG, Weddell Gyre; WOCE, World Ocean Circulation Experiment; WSBW, Weddell Sea Bottom Water; WSDW, Weddell Sea Deep Water.

* Corresponding author.

E-mail addresses: svenja.ryan@awi.de (S. Ryan),

michael.schroeder@awi.de (M. Schröder), ohuhn@uni-bremen.de (O. Huhn), ralph.timmermann@awi.de (R. Timmermann). the Weddell Sea to the total AABW formation, it is still regarded as a major source region by contributing roughly $40 \%$, followed by inputs from the Ross Sea, Adélie Land and Cape Darnely (Meredith, 2013).

A schematic of the circulation in the Weddell Sea and the adjacent Southern Ocean is shown in Fig. 1. The Weddell Gyre (WG) is a mainly wind-driven, cyclonic ocean gyre. The northern border is given by the Antarctic Circumpolar Current (ACC) which flows completely around Antarctica. Within the ACC, several oceanic fronts (light grey lines in Fig. 1) are known and are associated with sharp gradients in the isopycnals which are generally rising towards Antarctica (Deacon, 1937). For a detailed description of oceanic fronts in the Southern Ocean the reader is referred to Orsi et al. (1995). The WG boundaries are predominantly specified by topography, except in the east, where intense water mass exchanges between the gyre and the ACC take place (Schröder and Fahrbach, 1999; Gouretski and Danilov, 1993). Warm and saline water is injected at the eastern boundary (marked in yellow) originating from Circumpolar Deep Water (CDW) (Orsi et al., 1993; Deacon, 1979; Gouretski and Danilov, 1994), which is called Warm Deep Water (WDW) once entering the WG. Along its way in the gyre, WDW is modified by upwelling into and mixing with the surface layer to compensate the heat loss at the surface. This water mass, then called modified Warm Deep Water (mWDW) (red dotted line), makes its way to the southern Weddell Sea crossing 


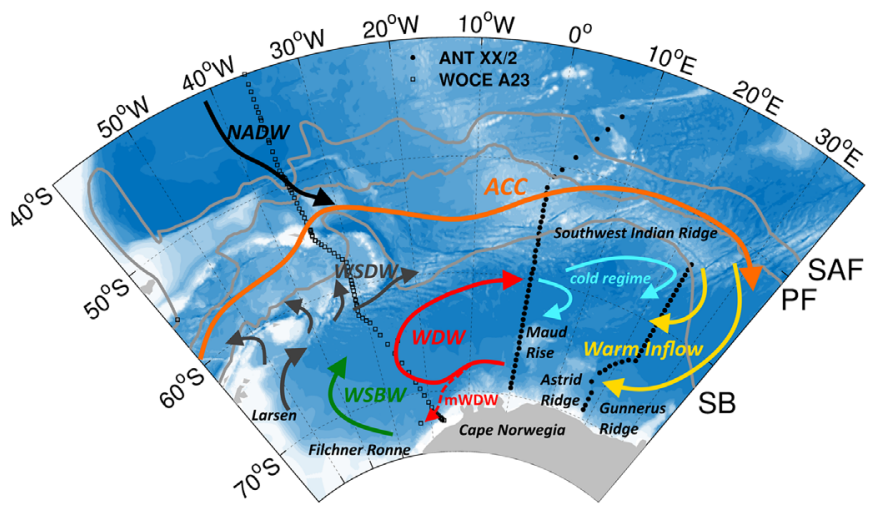

Fig. 1. Schematic circulation of the Weddell Gyre. Black dots are stations along the eastern and Greenwich section from ANT XX/2 and black squares show stations from the WOCE A23 cruise. The light grey lines indicate oceanic fronts (after Orsi et al., 1995), which are labelled on the right hand side (SAF=Subantarctic Front; $\mathrm{PF}=$ Polarfront; $\mathrm{SB}=$ Southern Boundary). (For interpretation of the references to colour in the text, the reader is referred to the web version of this paper.)

the shelf break towards the Filchner-Ronne Ice Shelf (FRIS) and the Larsen Ice Shelf (LIS). Cooling of the intruded mWDW and brine rejection due to sea ice formation during winter form High Salinity Shelf Water (HSSW) (Nicholls et al., 2009). HSSW is the key water mass contributing to the Weddell Sea Deep Water (WSDW) and Weddell Sea Bottom Water (WSBW), and ultimately the AABW formation. These waters follow the continental slope to the north as part of the cyclonic gyre circulation and the light enough ones exit the basin through several gaps within the South Scotia Ridge System (dark grey arrows) (Naveira Garabato et al., 2002; Palmer et al., 2012; van Caspel et al., 2015). However, there are fractions of WDW which are not involved in dense water formation and follow the general circulation back to the northeast of the WG. On its way the water cools significantly so that the densest class of CDW forms the so-called 'cold regime' (Gordon and Huber, 1984) west of the Greenwich meridian (GM) (light blue), which is characterised roughly by potential temperatures $(\Theta)$ between $0{ }^{\circ} \mathrm{C}$ and $0.5^{\circ} \mathrm{C}$. This water partly recirculates at the open eastern boundary and mixes with the incoming warm water. Along with the term 'cold regime', the warm inflow in the south is called 'warm regime' and comprises waters with temperatures of 0.5$1.5^{\circ} \mathrm{C}$. Because of the importance of the deep and bottom waters for the global thermohaline circulation, variations in bottom water formation in the Weddell Sea have been an ongoing research topic in the past. Repeated measurements along the GM (Smedsrud, 2005; Fahrbach et al., 2011) are used to monitor the inflow of WDW. Significant variations of water mass properties for the
Weddell Sea Deep and Bottom Waters as well as the WDW were detected, accompanied with a positive trend (1984-2008) in the average temperature and salinity of the whole water column (Fahrbach et al., 2011). Variations of the water mass properties were attributed to variations in the inflow of CDW at the eastern boundary, being caused by asymmetric wind forcing at the northern and southern limb of the gyre. Furthermore, Fahrbach et al. (2011) state that redistribution of heat and salt by internal processes is responsible for the long-term increase of temperature and salinity of the WDW.

Warm Deep Water: properties and origin: Warm Deep Water $\left(0^{\circ} \mathrm{C} \leq \Theta \leq 1.5^{\circ} \mathrm{C}\right)$, being the only source of heat for the WG (besides solar radiation), originates from $\mathrm{CDW}$ which represents, by volume, the most dominant water mass of the ACC. After entering the Atlantic sector via the Drake Passage, the lower parts of CDW are altered by upwelling NADW (black arrows in Fig. 1) at the Antarctic convergence zone, and also by recently ventilated water masses leaving the WG to the north (Whitworth and Nowlin, 1987; Reid et al., 1977; Orsi et al., 1993). As the latter have a higher density than waters found outside the gyre, they sink once leaving the Weddell basin while the lighter CDW is displaced upwards in the water column. The WOCE A23 section shows the interactions between these water masses (Heywood and King, 2002). For orientation, the section is also marked in Fig. 1. According to different hydrographic properties it is common to separate CDW into lower and upper CDW (LCDW, UCDW; see Fig. 2). LCDW is characterised by a salinity maximum due to the influence of the NADW (Patterson and Whitworth, 1990), while the UCDW in the Atlantic sector is classified as the layer with minimum oxygen and maximum nutrient (phosphates, nitrates) concentration (Larque et al., 1997; Saunders and King, 1995; Vanicek and Siedler, 2002), which are properties gained in the Indian and Pacific sectors. CDW enters the WG between 15 and $30^{\circ} \mathrm{E}$, a region characterised by meanders and eddies (Schröder and Fahrbach, 1999; Gouretski and Danilov, 1993, 1994) in association with the southward turn of the ACC in the vicinity of the Southwest Indian ridge. Hence, there is no closed boundary in the east and the inflow may be highly variable. Park et al. (2001) show evidence of the eastern boundary extending far beyond $30^{\circ} \mathrm{E}$. They speak of two modes of the formation of the warm regime. One is the eddy-mixing between the cold regime and the ACC north of $60^{\circ} \mathrm{S}$ between 20 and $30^{\circ} \mathrm{E}$, where the authors refer to Schröder and Fahrbach (1999). The second mode is based on their findings and is given by direct westward advection along the southern limb of the gyre. It consists of gradually upwelled CDW which can be modified by surrounding Antarctic slope and shelf waters.

The hydrographic data presented in this study shows both
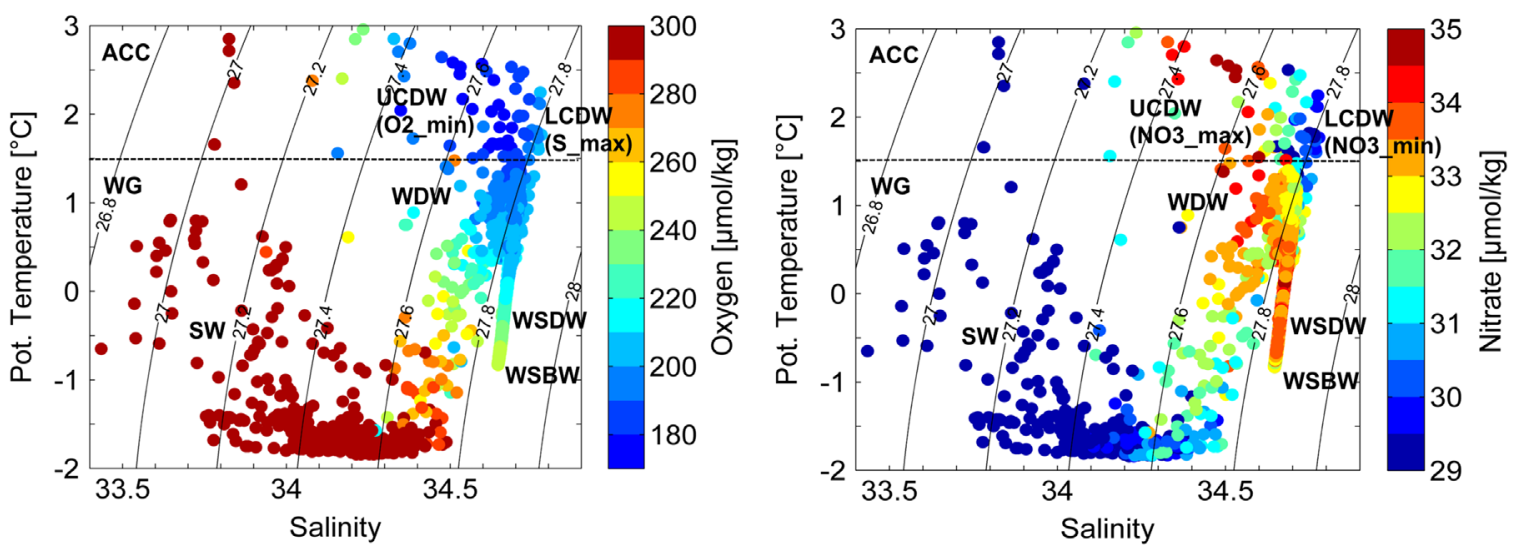

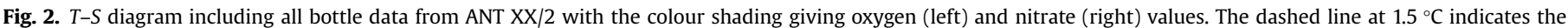
border between ACC and WG waters. (For interpretation of the references to colour in this figure caption, the reader is referred to the web version of this paper.) 
Table 1

Source water type definitions plus the according weight used for the OMP analysis and the limits chosen for the Monte Carlo approach.

\begin{tabular}{lllll}
\hline SWT & $\Theta\left[{ }^{\circ} \mathrm{C}\right]$ & $\mathrm{S}[\mathrm{psu}]$ & $\mathrm{O}_{2}[\mu \mathrm{mol} / \mathrm{kg}]$ & $\mathrm{NO}_{3}[\mu \mathrm{mol} / \mathrm{kg}]$ \\
\hline $\mathrm{S}_{\max }$ at SB $\left(\mathrm{SWT}_{1}\right)$ & 1.68 & 34.74 & 192 & 30.24 \\
$\mathrm{O}_{2}$-min at $\mathrm{SB}\left(\mathrm{SWT}_{2}\right)$ & 1.66 & 34.64 & 174.21 & 33.5 \\
WDW cold regime $\left(\mathrm{SWT}_{3}\right)$ & 0.43 & 34.69 & 194 & 34.8 \\
Mixed layer $\left(\mathrm{SWT}_{4}\right)$ & -0.7 & 34.3 & 325.53 & 29.55 \\
Weight & 1 & 1 & 0.3 & 0.3 \\
Limit & \pm 0.1 & \pm 0.05 & \pm 5 & \pm 0.75 \\
\hline
\end{tabular}

modes combined in one section located at the eastern boundary of the WG. Two maximum potential temperature cores reveal different ventilation signals. The presence of two modes is supported by model results. We discuss the dynamics which set up these two modes and perform an Optimum Multiparameter (OMP) analysis to gain more insight on the origin of the cores within the ACC.

\section{Data and methods}

\subsection{Observational data}

The hydrographic data set used was obtained during the ANT XX/2 RV Polarstern cruise taking place from 24 November 2002 to 23 January 2003 (Fütterer and Kattner, 2005; Schröder and Wisotzki, 2010). In total, 143 stations were sampled along three transects, from which only two are analysed in this study. One being located along the GM between $52^{\circ} \mathrm{S}$ and the continent, which was fully covered by ice and one eastern transect centred around $20^{\circ} \mathrm{E}$, between $54^{\circ} \mathrm{S}$ and the coast (Fig. 1). The main focus is on the eastern transect as it is located at the eastern boundary of the WG, where in situ measurements are rare. Some sea ice was still remaining in the south, while the northern part was ice free (Bakker et al., 2008). Vertical profiles of temperature and salinity were obtained from a SBE 911 + CTD (conductivity-temperaturedepth) sonde with a sampling frequency of $24 \mathrm{~Hz}$. The sonde was mounted on a rosette with 24 Niskin bottles with a capacity of 121 each. Additional sensors such as one oxygen sensor were attached.

Calibrations of the conductivity and temperature sensors were obtained by Seabird Electronics before and after the cruise. The conductivity was corrected by salinity measurements from water samples performed with the Guildline Precision Salinometer (OPS). The resulting accuracy is at least 0.003 for salinity, $0.003{ }^{\circ} \mathrm{C}$ for temperature, and $2 \mathrm{db}$ for pressure. Data from the oxygen sensor was corrected by oxygen values from water samples measured via the Winkler method with a Dissolved Oxygen Analyser.

Additional water samples were taken to obtain Chlorofluorocarbon (CFC) concentrations, which serve as an anthropogenic tracer. The samples were flame-sealed on board and analysed after the cruise with a gas chromatograph. Nutrient concentrations were also drawn from water samples by using a Technicon autoanalyser II.

Since the inflow of CDW/WDW is confined to the upper $1000 \mathrm{~m}$, we choose to limit our analysis to this depth range, which coincides roughly with the $0.5^{\circ} \mathrm{C}$ isotherm in the southeastern WG.

\subsection{Model analysis}

The circumpolar ice-ocean model Bremerhaven Regional Ice Ocean Simulations (BRIOS) (Timmermann et al., 2002) has been used to investigate the variability of the eastern boundary of the WG and possible inflow patterns. The model is run on a circumpolar grid which covers the Southern Ocean south of $50^{\circ} \mathrm{S}$ with a horizontal resolution of $1.5^{\circ}$ in the zonal and $1.5^{\circ} \cos \phi$ in the meridional direction, with $\phi$ being the latitude. The vertical domain is split into 24 layers with a higher resolution at the bottom and the surface. All major Antarctic ice shelves are included. The simulations were forced with reanalysis data from the National Centers for Environmental Prediction (NCEP) for the 1958-2014 period.

\subsection{Optimum multiparameter analysis}

The OMP (Tomczak, 1981; Tomczak and Large, 1989; Huhn et al., 2008) is a method to quantify the fractions $f_{i}$ of defined Source Water Types (SWT) with characteristic properties $X_{i}$ which mix and form the observed characteristics $X_{\text {obs }}$ at a certain data point. This data point must lie downstream of the formation region of the SWTs. A further requirement is mass conservation $\left(\sum f_{i}=1\right)$. The number of SWT must be equal to or better smaller than the number of conservative properties plus one, to avoid under-determination of the equation system.

$X_{\mathrm{obs}}=\sum f_{i} X_{i}$

By inverting the linear system (Eq. (1)) in a least-squares sense, the optimal combination of SWT fractions $f_{i}$ is obtained. The equation is normalised by the mean and variance of each SWT and each parameter is weighted (see Table 1) to account for uncertainties. Residuals between the computed and observed properties are used as a skill measure for the conducted OMP. In this study potential temperature, salinity, oxygen, and nitrate are used as properties. Although biological activity can influence oxygen and nutrient concentrations, the influence on our data is neglected here as the defined SWTs are limited to small oxygen values compared to surface values. The choice of the SWTs is difficult in our case as no typical water masses with fixed definitions can be used, which will be dealt with in Section 3.4.

\section{Results}

\subsection{Hydrographic observations}

Eastern boundary: Fig. 3 shows potential temperature (top) and oxygen (bottom) of the upper $1000 \mathrm{~m}$ along the eastern section of ANT XX/2. A clear structure can be seen below the thermocline which separates the cold northern branch of the WG from the warmer ACC $\left(\sim 55^{\circ} \mathrm{S}\right)$. Within the gyre, the warm inflow $\left(\Theta>0.8^{\circ} \mathrm{C}\right.$ ) is found south of roughly $59^{\circ} \mathrm{S}$ being in agreement with other hydrographic sections at $20^{\circ} \mathrm{E}$ (Orsi et al., 1993; Huber et al., 1981). Cooler temperatures around $0.5^{\circ} \mathrm{C}$ are found in the northern limb of the gyre which are recirculating remnants of cold regime waters. This cooler part is characterised by doming isopycnals (grey lines). In the warm regime a shoaling of isopycnals causes upwelling of WDW. The WDW reveals a striking two-core structure with maximum temperatures located at $60^{\circ} \mathrm{S}$ around $300 \mathrm{~m}$ depth $\left(\Theta \approx 1.5^{\circ} \mathrm{C}\right)$ and a second larger core centred around $65^{\circ} \mathrm{S}$ which is shallower (200 $\mathrm{m}$ depth) with a temperature over $1.3^{\circ} \mathrm{C}$. For convenience we call the core at $60^{\circ} \mathrm{S}$ 'core $1^{\prime}$ ( $(\mathrm{C} 1)$ and the core further south 'core 2' (C2). The shape of the density lines within core 1 indicate the presence of an anticyclonic eddy, which is also seen in geostrophic velocities (not shown). A second warm core eddy is found further north in the cold regime $\left(58^{\circ} \mathrm{S}\right)$ with a maximum potential temperature around $0.6^{\circ} \mathrm{C}$. The oxygen section (Fig. 3, bottom) generally shows low values $(<200 \mu \mathrm{mol} / \mathrm{kg})$ for the warm inflow, being derived from CDW. Minimum values (within the gyre) coincide with core 2 with $\mathrm{O}_{2}<190 \mu \mathrm{mol} / \mathrm{kg}$, while core 1 shows higher values, close to $200 \mu \mathrm{mol} / \mathrm{kg}$. Within the cold 

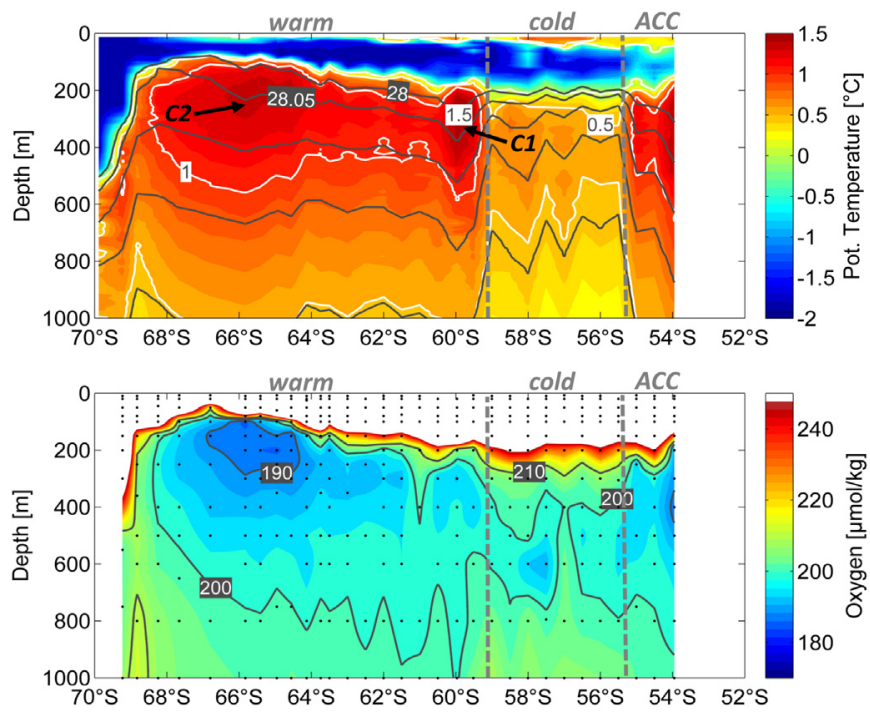

Fig. 3. Section East ANT XX/2. Grey, dashed vertical lines separate regimes based on temperature. Top: potential temperature, with white contours in $0.5{ }^{\circ} \mathrm{C}$ intervals. Grey contours display neutral density with an $0.05 \mathrm{~kg} / \mathrm{m}^{3}$ interval between 28 and $28.2 \mathrm{~kg} / \mathrm{m}^{3}$. Black arrows indicate the position of the two cores C1 \& C2. Bottom: oxygen (bottle data) with grey contours in a $10 \mu \mathrm{mol} / \mathrm{m}^{3}$ interval. Small black dots indicate where samples were taken.

regime the density range of the cores is characterised by much higher oxygen values. Here, the low oxygen layer is confined to deeper and denser layers, while in the ACC the distribution is similar to the warm regime.

Since the strongest difference between the cores is seen in oxygen (Fig. 3), CFC-12 is used as an additional parameter. While the oxygen concentration can be influenced by biogeochemical processes (even though we assume this influence to be small), CFC is an anthropogenic, stable tracer and thus more significant for making statements about ventilation even though it is time dependent. Fig. 4 shows CFC-12 of the upper $1000 \mathrm{~m}$ where unfortunately, not many samples have been taken. For our analysis, there are only data points between 400 and $600 \mathrm{~m}$ available. Maximum values are associated with the latitudes of the two warm core eddies at $60^{\circ} \mathrm{S}$ and $58^{\circ} \mathrm{S}$. Although they are found the same depth, they lay on different density levels, due to the doming isopycnals in the cold regime. South of $60^{\circ} \mathrm{S}$, small values around $0.2 \mathrm{pmol} / \mathrm{kg}$ characterise the layer between the neutral densities $\gamma_{n}=28.1-28.15 \mathrm{~kg} / \mathrm{m}^{3}$. At the Southern Boundary (SB) a strong gradient is found between low CFC-12 at the northern edge of the cold regime and elevated values in the ACC. The latter are found on the same isopycnal $\left(\gamma_{n}=28.1 \mathrm{~kg} / \mathrm{m}^{3}\right)$ as the high value at $60^{\circ} \mathrm{S}$.

Properties of selected stations are shown in Fig. 5 in order to compare profiles of different regions. For the eastern section core 1 (green) and 2 (blue) were chosen together with the profile of the warm core eddy in the cold regime (red). These are compared to stations in the cold regime (purple, cyan), one station at the SB

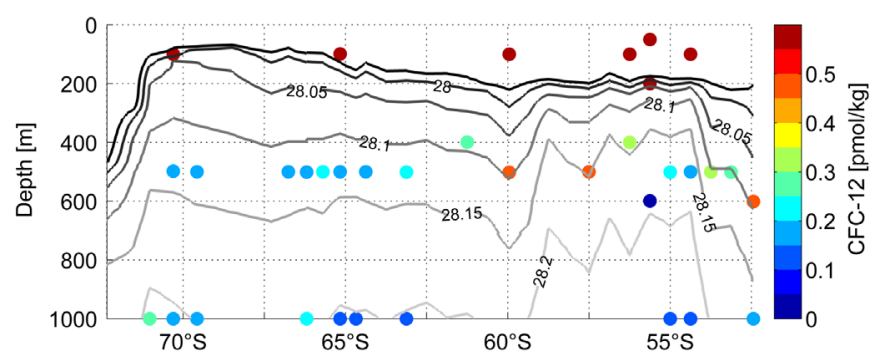

Fig. 4. $\mathrm{CFC}-12$ (dots) obtained from water samples during ANT $\mathrm{XX} / 2$. Grey lines give the neutral density. Surface values (CFC $-12>1 \mathrm{pmol} / \mathrm{kg}$ ) have been excluded. (grey), and one station located between the SB and Polar Front (PF) (mustard), all along the GM. Both stations representing the cores can be grouped with the ACC waters, while the warm eddy at $58^{\circ} \mathrm{S}$ shows a profile more characteristic for the cold regime. The clearest separation can be done for neutral densities lighter than $28.1 \mathrm{~kg} / \mathrm{m}^{3}$, while the profiles converge for denser waters. However, the shape of the profiles indicate that the cold regime waters are remnants of the densest inflowing warm water. The green profile, representing core 1 , reveals a large variability below the maxima of potential temperature and salinity which supports our previous observations regarding core 1 being an eddy. Its profile is overall located between the one of the SB and the one between both fronts. Only for densities larger than $28.1 \mathrm{~kg} / \mathrm{m}^{3}$ is an overlap with the red profile found. Below $\gamma_{n}<28 \mathrm{~kg} / \mathrm{m}^{3}$, all profiles converge and show the transition from WDW (inflow \& recirculation) to WSDW.

Greenwich Meridian: Potential temperature and oxygen concentrations along the GM are displayed in Fig. 6 representing a downstream picture of the warm inflow (WDW). Several small warm core features can be seen at a depth of roughly $200 \mathrm{~m}$ with temperatures between 0.8 and $1{ }^{\circ} \mathrm{C}$. The WDW here is significantly cooler and denser than observed at the eastern section, likely to be caused by the admixture of cold regime water. At $66^{\circ} \mathrm{S}$, the influence of Maud Rise can be seen in form of a Taylor column present on top of it (Beckmann et al., 2001), causing the warm water to flow around. At the GM, the cold regime is generally cooler than at $30^{\circ} \mathrm{E}$, but still shows temperatures over $0.5^{\circ} \mathrm{C}$ between the 200 and $400 \mathrm{~m}$ depths, during the time of the data acquisition. Only two stations show maximum potential temperatures below $0.5^{\circ} \mathrm{C}$. The cold regime has a larger meridional extent than the warm regime and the SB is located further south $\left(\sim 56^{\circ} \mathrm{S}\right)$ compared to the eastern section. Within the ACC temperatures exceed $1.6^{\circ} \mathrm{C}$ and the neutral density lines deepen, so that the neutral-density surface for $\gamma_{n}=28.05 \mathrm{~kg} / \mathrm{m}^{3}$, which has a depth of $100 \mathrm{~m}$ in the warm regime, is found at around $1000 \mathrm{~m}$ or deeper in the ACC (see Fig. 10).

Oxygen concentrations (Fig. 6, bottom) for the warm cores exhibit local minima (warm regime) with values of $196 \mu \mathrm{mol} / \mathrm{kg}$. The absolute minimum within the WG is found at $60^{\circ} \mathrm{S}$ with $\mathrm{O}_{2}=180 \mu \mathrm{mol} / \mathrm{kg}$. It is part of a large low-oxygen patch with a vertical extent of almost $400 \mathrm{~m}$, representing the intermediate waters of the central WG. They are derived from the CDW, which has been modified by biochemical processes, generating an oxygen minimum and nutrients maximum (Whitworth and Nowlin, 1987). Mean zonal velocities show that the centre of the WG circulation at the GM is located around $60^{\circ} \mathrm{S}$ (Klatt et al., 2005). Within the ACC, minimum oxygen values $\left(\mathrm{O}_{2}<180 \mu \mathrm{mol} / \mathrm{kg}\right)$ characterise the Upper Circumpolar Deep Water (UCDW), which is seen in the section north of $54^{\circ} \mathrm{S}$. At $58^{\circ} \mathrm{S}$, directly south of the SB, the $200 \mu \mathrm{mol} / \mathrm{kg}$ oxygen isoline is almost a straight line between 200 and $900 \mathrm{~m}$ depth. This feature has been observed before and is also visible in repeat CFC sections along the GM (Huhn et al., 2013).

\subsection{Snap shot vs. time-mean state}

Model results: Fig. 7 shows two months of a climatological annual cycle (monthly mean values) of the simulated barotropic stream function in the WG region obtained from a BRIOS-2 model output. It exhibits the typical two-core cyclonic gyre circulation, with one core located in the northeastern and one in the central Weddell Sea. The weakest transport is found in December and January (Fig. 7, left) while the WG circulation is strongest in May (Fig. 7, right). In the area of the eastern inflow straight streamlines are found leading from the northeastern end to the GM, indicating a persistent inflow in this region. However, the stream function also indicates a southern pathway stretching beyond $30^{\circ} \mathrm{E}$ before 

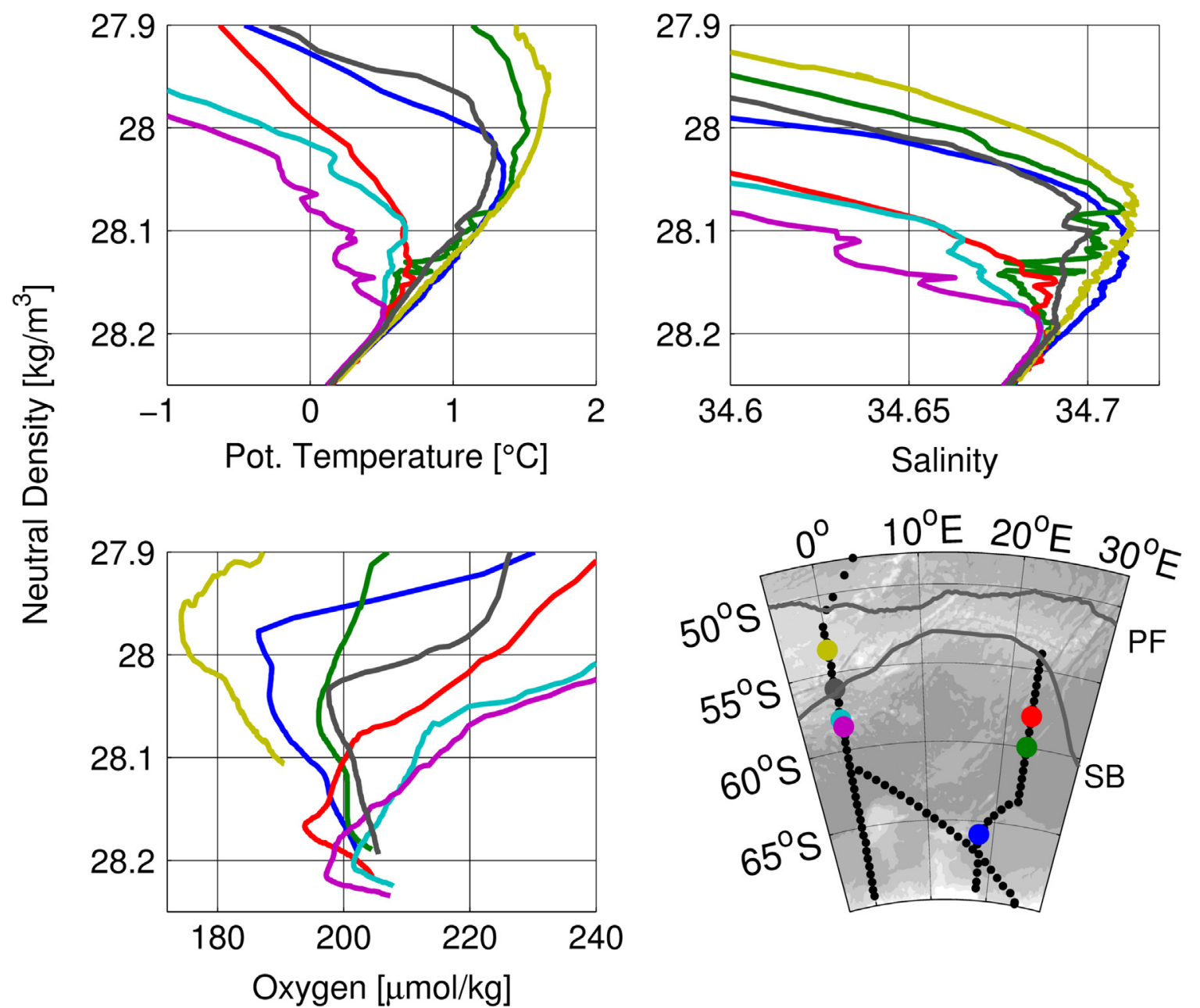

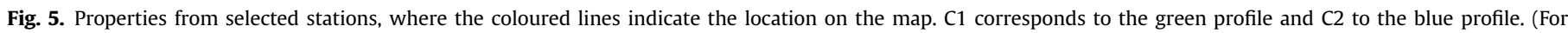
interpretation of the references to colour in this figure caption, the reader is referred to the web version of this paper.)
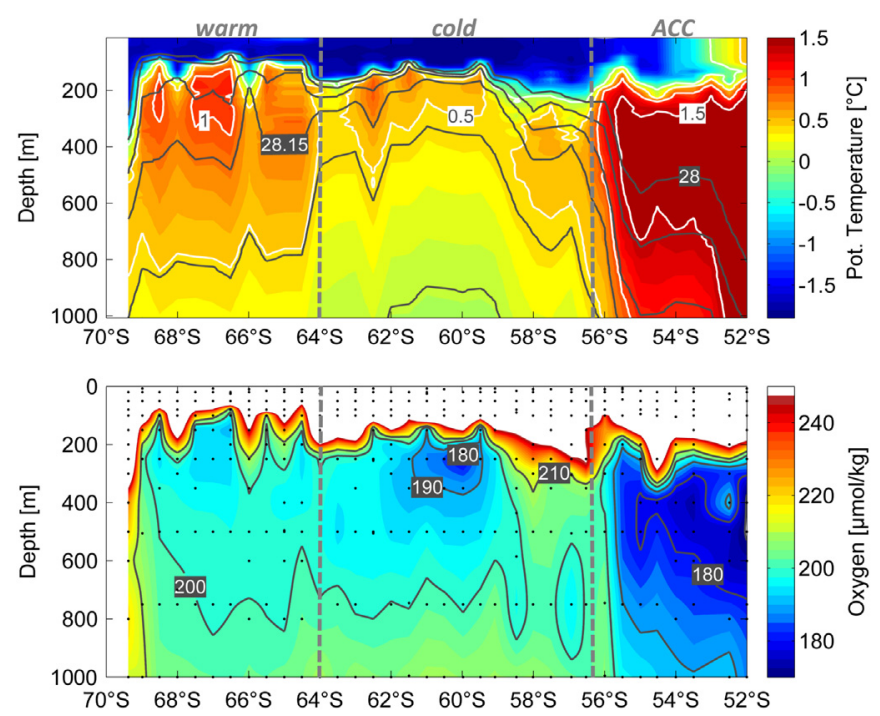

Fig. 6. Section West ANT XX/2. Grey, dashed vertical lines separate regimes based on temperature. Top: potential temperature, with white contours in $0.5^{\circ} \mathrm{C}$ interval. Grey contours display neutral density with an $0.05 \mathrm{~kg} / \mathrm{m}^{3}$ interval between 28 and $28.25 \mathrm{~kg} / \mathrm{m}^{3}$. Bottom: oxygen (bottle data) with grey contours in a $10 \mu \mathrm{mol} / \mathrm{m}^{3}$ interval. Small black dots indicate where samples were taken. turning westward at about $65^{\circ} \mathrm{S}$. This branch is relatively weak in January with $5 \mathrm{~Sv}\left(1 \mathrm{~Sv}=10^{6} \mathrm{~m}^{3} / \mathrm{s}\right)$ but is more developed in May, when up to $15 \mathrm{~Sv}$ get transported via the southern route, accompanied by an, in general, stronger gyre. This structure is a first hint that the observed cores during ANT XX/2 represent a typical inflow pattern at the eastern boundary of the WG, which exhibits seasonal variability. One has to keep in mind that the barotropic stream function might only display a time-mean picture of the highly variable inflow area.

As a next step, interannual variability is analysed based on three-month means (November, December, January) of the barotropic stream function from the same model. We chose this time period as it corresponds to the situation preceding the available measurements from ANT XX/2. Even though the annual cycle shows a stronger stream function and a more pronounced southern branch in austral winter, we have excluded the winter period from the averaging due to the lack of observations during this time. Hence, the results shown here would be similar, or even intensified if winter circulation was included. Selected years are shown in Fig. 8. Besides variations in the strength of the gyre, the eastern boundary exhibits considerable year-to-year variability, with a more or less pronounced southern pathway. In 2009 the latter has completely vanished and the inflow occurs on the northeastern edge only. In other years the $5 \mathrm{~Sv}$-streamline 
a

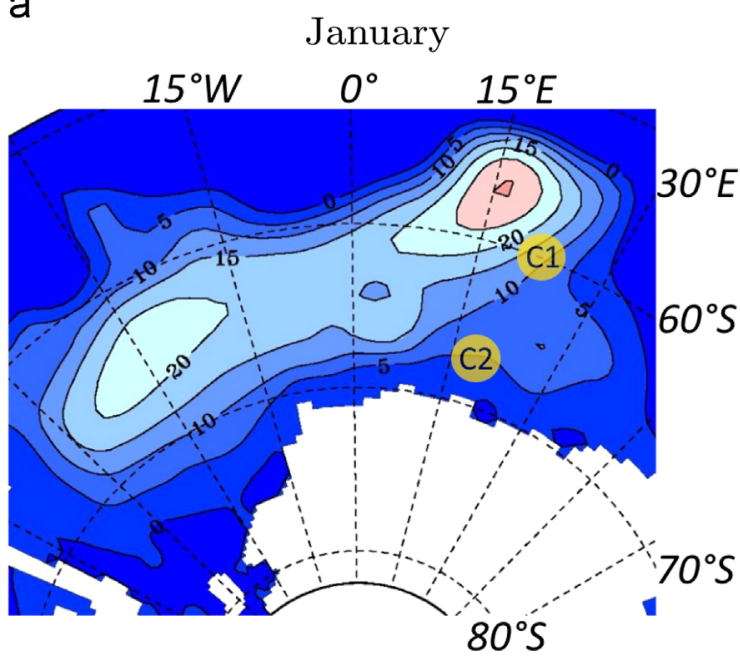

b

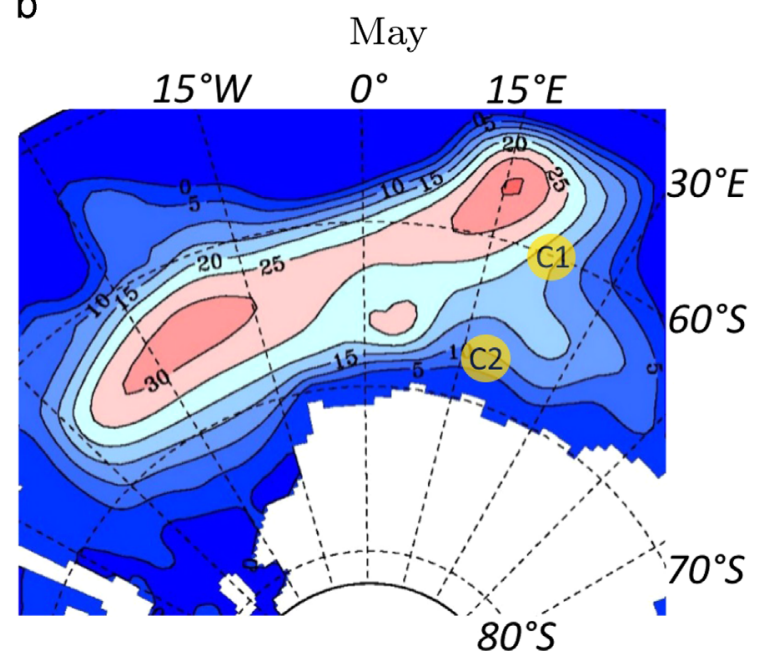

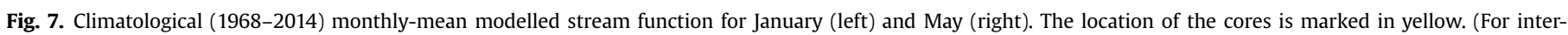
pretation of the references to colour in this figure caption, the reader is referred to the web version of this paper.)

indicates a permanent weak inflow in the south, which can reach up to $10 \mathrm{~Sv}$ in some years (e.g. 1978 and 1999). The model results indicate that there is substantial variability causing changes in the inflow paths on a seasonal but also interannual basis, which is important to keep in mind for analysing variability further downstream, i.e. at the GM.

To summarise, on seasonal and interannual time scales the two different inflow pathways seem to be a persistent feature in the eastern WG time-mean field.

\subsubsection{Hydrographic climatology}

Another option to analyse the time-mean field is looking at hydrographic climatologies, even though they have to be viewed carefully in an undersampled region like the eastern WG. We chose the CSIRO Atlas of Regional Seas (CARS) argo-only climatology, as we believe that ARGO floats provide a better spatial coverage of the inflow region, as ship measurements are mostly done along specific sections only.

Fig. 9(a) shows potential temperature at $300 \mathrm{~m}$ depth. A broad warm inflow can be seen at the eastern boundary, which gets narrower during its westward propagation. However, it is impossible to distinguish between two pathways based on the temperature field alone. Since Park et al. (2001) pointed out two different modes of the warm inflow with a turbulent eddydominated shorter route and a longer advective route further south, we plotted the standard deviation of the climatological temperature field at $300 \mathrm{~m}$ depth (Fig. 9(b)). The highest standard deviation is found in the northeastern corner where the ACC turns southward, associated with turbulent eddy field in this region. A band of high variability spreads south westward towards $20^{\circ} \mathrm{E}$, $60^{\circ} \mathrm{S}$, the location where core 1 is located. What looks like a persistent inflow in the stream function is likely a time-mean picture of a pathway set up by transient eddies. Further south, the standard deviation seems to decrease, which would be in agreement with an advective southern branch.

\subsection{Dynamics of the eastern inflow}

As mentioned in the introduction the circulation in the northeastern corner of the WG is influenced by a gap in the Southwest Indian ridge, causing a southward turn of the ACC. By laws of vorticity dynamics, both circulation (vorticity flux) and volume are conserved as well as their ratio called potential vorticity. The barotropic part of the circulation is assumed to follow $\mathrm{f} / \mathrm{H}$ - contours, where $f$ is the Coriolis parameter and $H$ the total depth. Hence, there is always competition between the magnitude of effects of topography and Earth's rotation on the flow. Fig. 10a displays the $f / H$-contours plotted over bathymetry, which show the strong topographic influence of the ridge including the southwestward turn near the gap (see red arrow), where the depth increases. The contours agree with the inner pathway found in the model results and trajectories. Once the flow has been deflected to the south, moving away from the ridge, the topographic effect will become smaller while the planetary effect will increase. The latter means that a southward displacement will introduce an anticyclonic rotation, i.e. an eastward motion which can be seen at the nearly zonal contour at $60^{\circ} \mathrm{S}$ (green arrow). This pattern might determine the shape of the outer pathway indicated in the model results and explains the anticyclonic rotation of the eddy associated with core 1. Gouretski and Danilov (1993) also find anticyclonic motion for eddies of circumpolar origin. Towards the continental shelf zonal isolines are disturbed by several small ridges named, from east to west, the Gunnerus ridge, Astrid ridge, and Maud Rise (see Fig. 1). Here, westward flow (blue arrow) is associated with the belt of easterly winds around Antarctica. Core 2 must emerge from waters that turn eastward first due to potential vorticity conservation but then enter the region of westward flow near the continent. While a large part of the warm water will proceed eastward, some will turn westward and form the southern, advective mode, which is in agreement with a possibly low standard deviation.

Basic fluid dynamics seem to be able to describe and explain the existence of two pathways but it is still not clear where exactly the two observed cores obtained their properties from, i.e. where they originated from. As shown in Fig. 5, the cores have a neutral density around $28.05 \mathrm{~kg} / \mathrm{m}^{3}$. To trace their origin in the ACC, the depth of this neutral density surface is shown in the right panel of Fig. 10. It becomes clear that waters found as shallow as $100 \mathrm{~m}$ in the WG are located at a depth between $400 \mathrm{~m}$ at the SB and over $1000 \mathrm{~m}$ in the centre of the ACC. Looking at oxygen along a meridional section across the ACC (i.e. Figs. 3 and 6), one finds that the waters near the transition zone of the ACC and the WG are slightly more ventilated than further north. Orsi et al. (1999) state that at the SB entrainment from Lower Circumpolar Deep Water (LCDW) into UCDW happens, which would diminish the oxygen minimum of UCDW. LCDW is significantly altered in the western Atlantic basin, where it gets into contact with newly formed water masses from the WG, causing a higher ventilation. Also the oxygen profile 
a

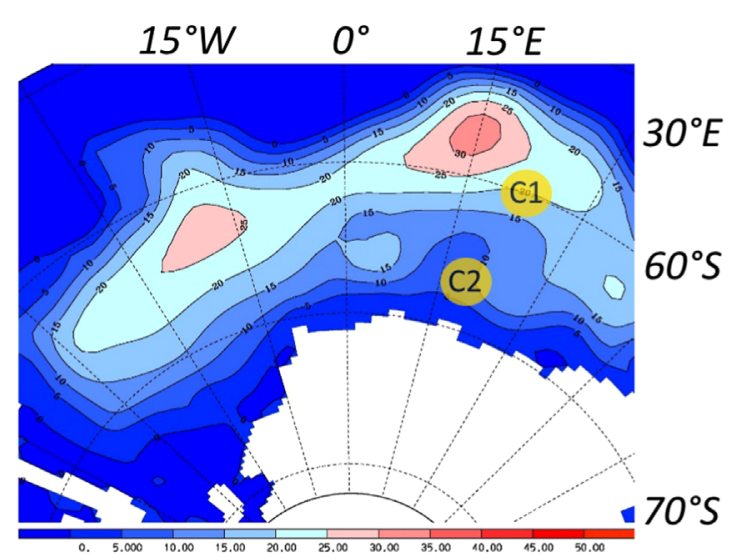

C

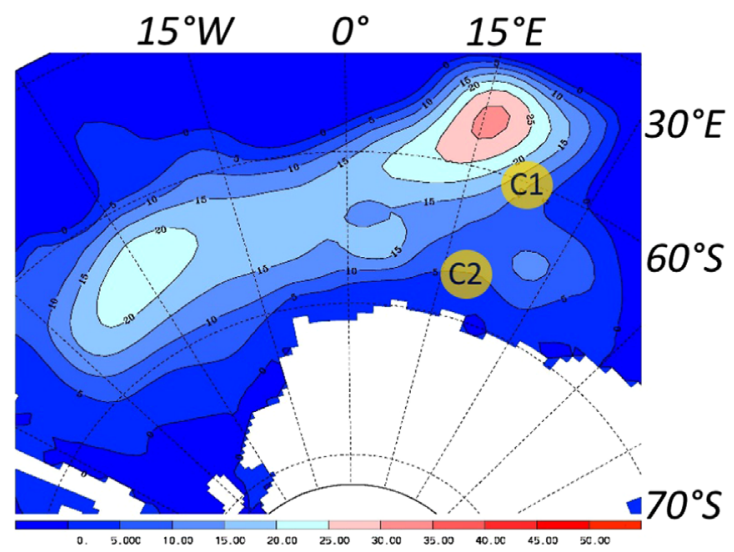

e

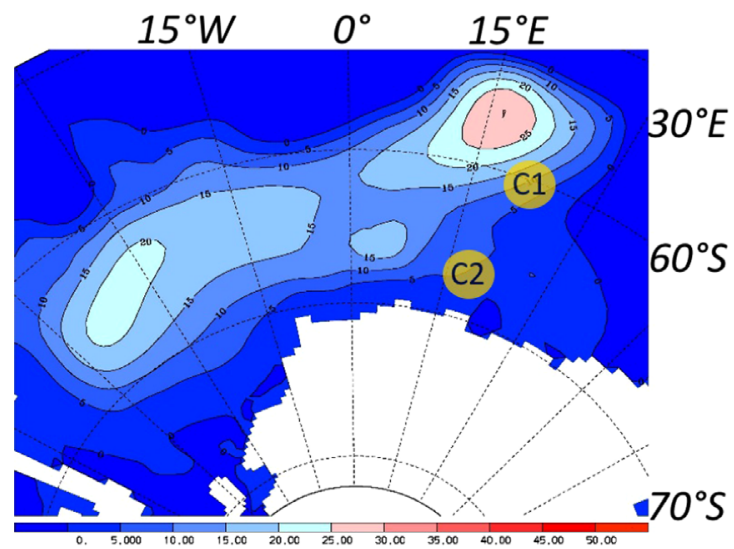

b

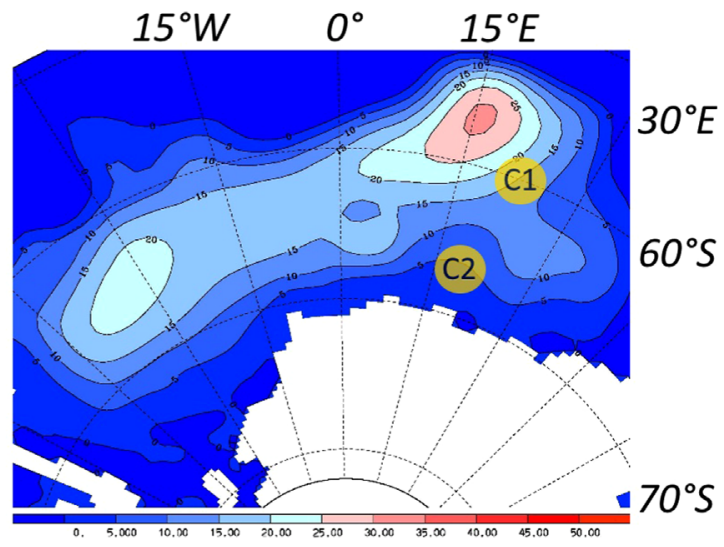

d

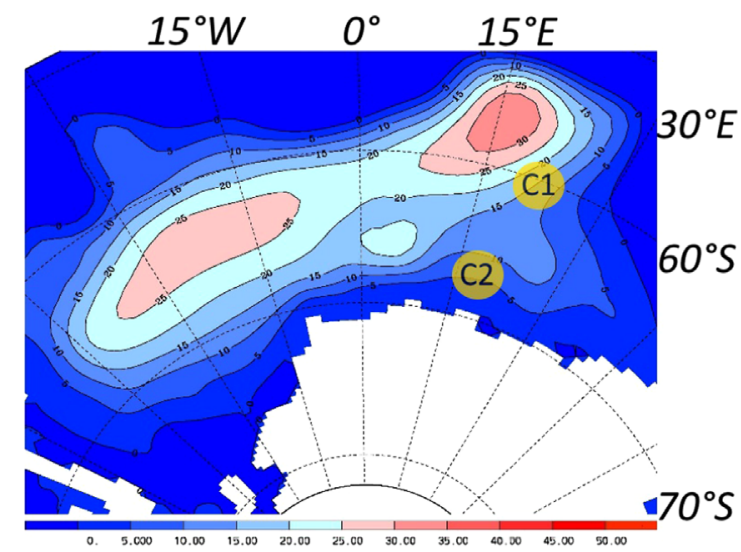

$f$

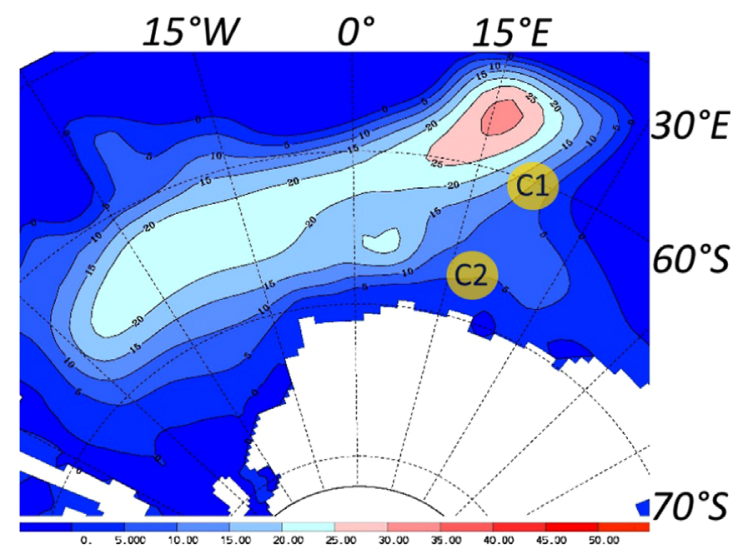

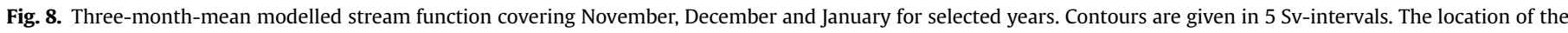
cores is marked in yellow. (For interpretation of the references to colour in this figure caption, the reader is referred to the web version of this paper.)

at the SB in Fig. 5 shows much higher values compared to the station north of it. This could explain the oxygen and CFC-12 values for core 1 , which would mean that core 1 was formed by an eddy carrying warm waters from the SB. To shed more light on the origin of the cores and the composition of the warm inflow in general we conduct an cOMP analysis involving four SWTs.

\subsection{Optimum multiparameter analysis results}

An OMP analysis was conducted for the eastern section and the GM from ANT XX/2, where the same four SWTs were used for both sections. Individual profiles of ANT-XX/2 were chosen to represent the different SWTs. SWT 1 is defined as the salinity maximum at the SB (Station 29), i.e. the LCDW, while $\mathrm{SWT}_{2}$ corresponds to the oxygen minimum layer (Station 31), which is characteristic for UCDW. The comparison of profiles in Fig. 5 let us draw the conclusion that the warm inflow mainly consists of ACC waters located near the SB or the centre, where the northern ACC waters proceed eastward. Since the cold regime waters meet the warm inflow at a highly variable northeastern corner of the WG, the third SWT was chosen to account for this water mass. The properties were taken from a station along the GM (Station 42). Finally, 
a

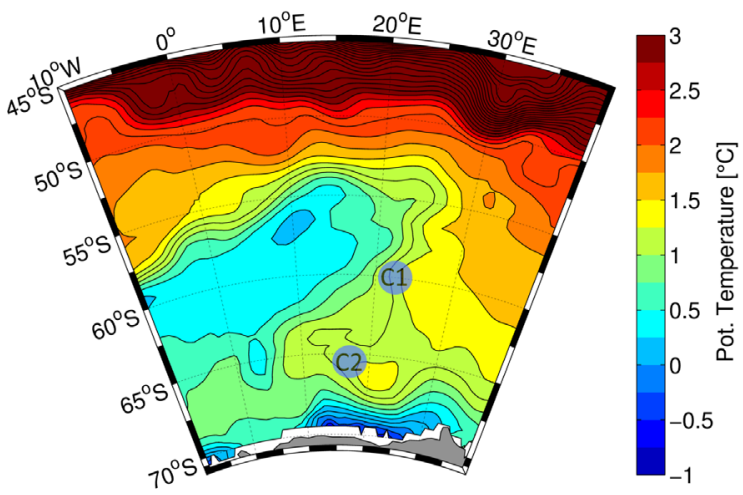

b

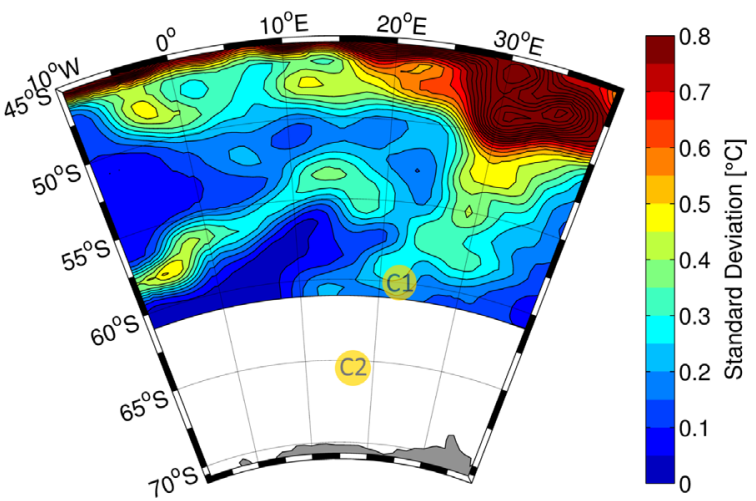

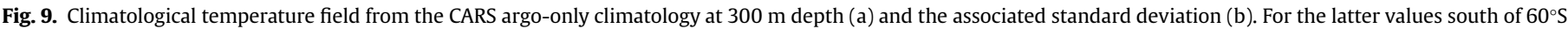
are not available.

a

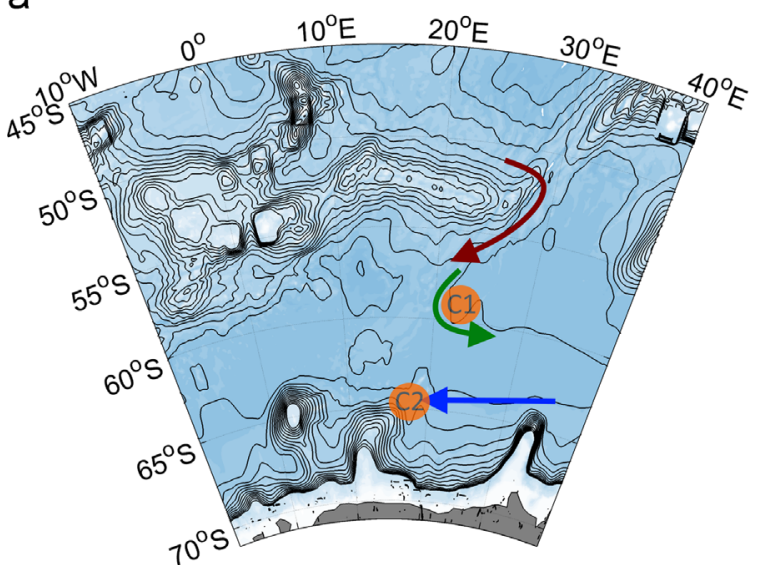

b

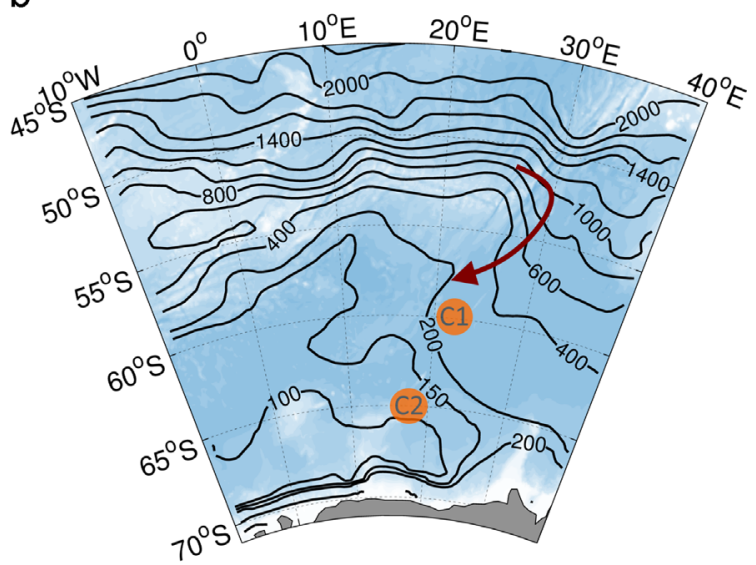

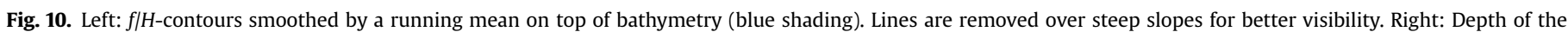

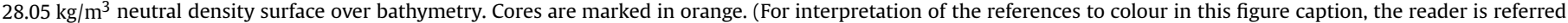
to the web version of this paper.)

a fourth SWT is introduced to see the impact of waters from the thermocline, laying just above the warm inflow. Table 1 shows the definition of each SWT and the associated weight for the analysis. Surface waters have been excluded from the analysis and are not shown in the results. All residuals lay within the accuracy of the measurements and the standard deviation, indicating that the OMP works well. As the OMP is very sensitive to the choice of SWTs a Monte Carlo approach has been used to perform 100 OMPs, where the individual properties of the SWTs were statistically changed within a chosen limit (see Table 1) in order to obtain error bars for the fractions (see titles in Fig. 11). Fractions along sections (latitude-depth) for each SWT at each data point are shown in Fig. 11.

Eastern boundary: The results for the eastern section are given in the left panels of Fig. 11. The top and middle represent the warm inflow (high fractions south of $59^{\circ} \mathrm{S}$ ) while the bottom panel shows the fractions for the cold regime water, which thus shows high fractions between $59^{\circ} \mathrm{S}$ and $55^{\circ} \mathrm{S}$. The warm regime is dominated by contributions from $\mathrm{SWT}_{1}$ and $\mathrm{SWT}_{2}$, where $\mathrm{SWT}_{1}$ occupies mainly the water column between 300 and $500 \mathrm{~m}$ depth and $\mathrm{SWT}_{2}$ shows higher fractions above this layer. Both SWTs exhibit maximum fractions of over $50 \%$, which in each case can be found at the latitude of the cores. The upper layer consists almost exclusively of $\mathrm{SWT}_{2}$ with small fractions of cold regime water $\left(\mathrm{SWT}_{3}\right)$, while the lower layer shows maximum fractions of $\mathrm{SWT}_{1}$ $(\approx 60 \%)$ around $450 \mathrm{~m}$ depth and a higher contribution of $\mathrm{SWT}_{3}$. Minimum fractions of cold regime water at $60^{\circ} \mathrm{S}$ support the presence of an isolated eddy, forming core 1 and transporting ACC waters. Smaller fractions of $\mathrm{SWT}_{3}$ around $58^{\circ} \mathrm{S}$ are in agreement with another warm eddy found in the observations. Here, $\mathrm{SWT}_{1}$ shows slightly higher fractions. In general the results introduce a clear vertical separation of the inflow, with low oxygen, and high nutrient waters $\left(\mathrm{SWT}_{2}\right)$ above the salinity maximum layer at roughly $400 \mathrm{~m}$ depth $\left(\mathrm{SWT}_{1}\right)$.

Greenwich Meridian: Further downstream at the GM (Fig. 11, right panels) a lot of mixing has already eroded the dominant signals of $\mathrm{SWT}_{1}$ and $\mathrm{SWT}_{2}$. The latter shows fractions close to zero except at a small patch south of Maud Rise. Most of this water mass would have been entrained into the surface mixed layer (Orsi et al., 1995). High fractions of the cold regime water show that, as indicated in Fig. 1, this water mass is admixed to the warm inflow on its way to Greenwich meridian, as the temperature difference of up to $0.5^{\circ} \mathrm{C}$ between the warm regime of the two sections indicates. The influence of the surface water is again negligible, hence the fractions of $\mathrm{SWT}_{3}$ are not shown.

\section{Discussion}

Our analysis has improved the understanding of the warm inflow at the eastern boundary of the WG and further established the existence of the two modes previously suggested by Park et al. (2001), where a shorter route is driven by eddy-mixing in the northeastern corner and a longer, more advective route exceeding 
a

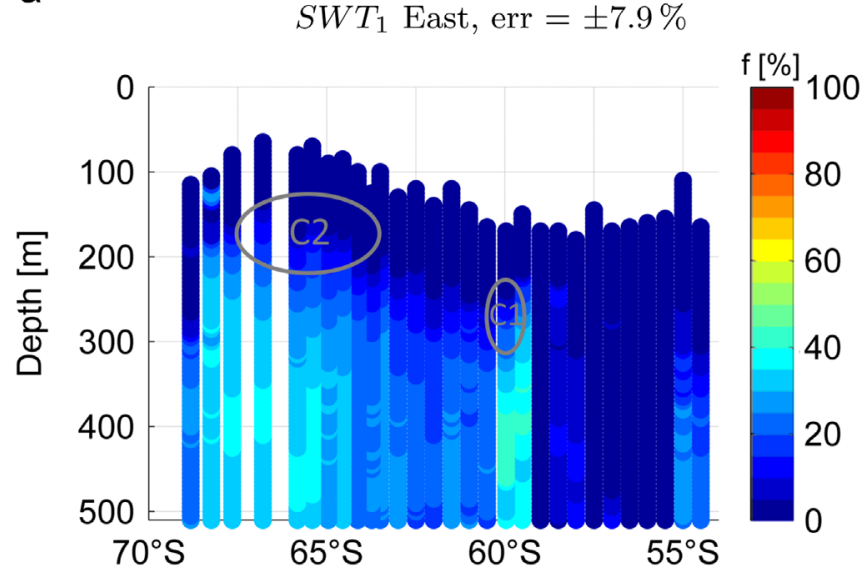

C

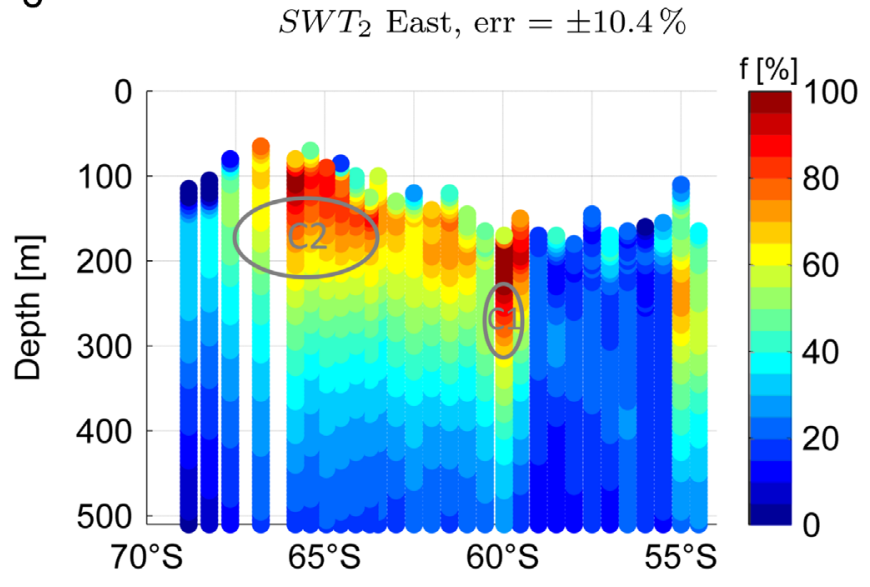

e

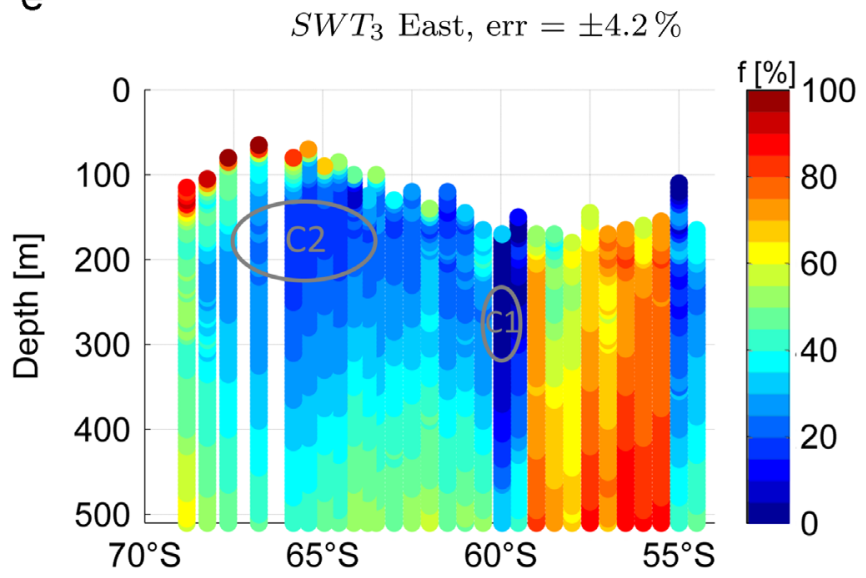

b

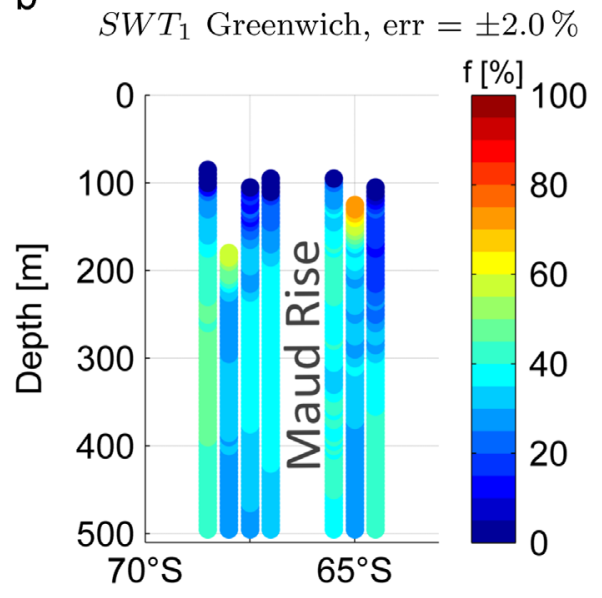

d

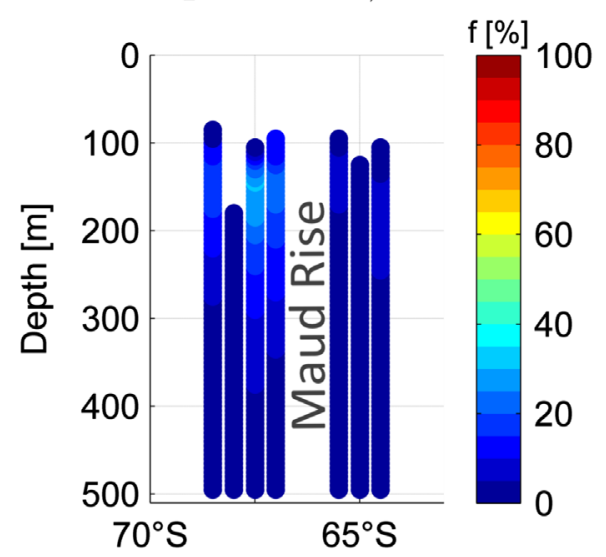

f

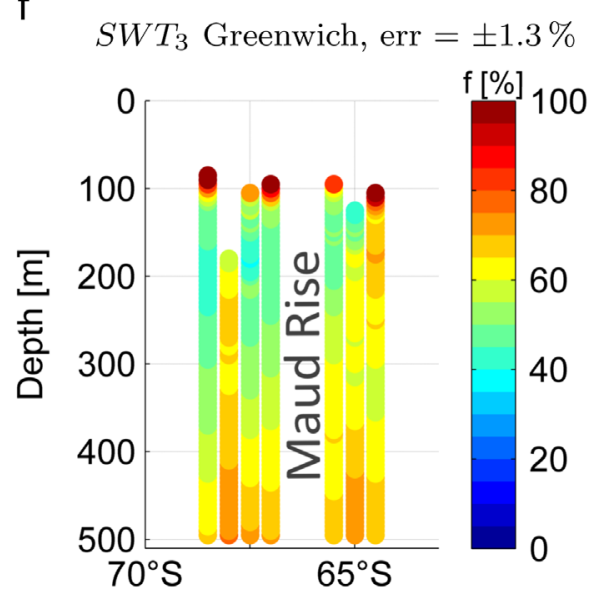

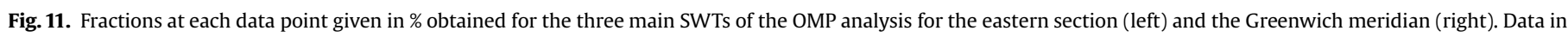
white areas has deliberately been left out.

$30^{\circ} \mathrm{E}$ forms the southern branch of the inflow.

The observations from ANT XX/2 are the first ones to exhibit both modes within one section, seen as two warm cores with maximum potential temperatures and salinities. Core 1 is located at the northern edge of the warm regime at $60^{\circ} \mathrm{S}$ and has properties of warm water found in the southern ACC, near the SB (Figs. 5 and 4). The shape of neutral density lines associate an anticyclonic rotation with the warm core. Thus, we believe that core 1 is an isolated eddy carrying waters from the SB into the WG, which is in agreement with the results of the OMP analysis showing no admixture of cold regime water. The eddy's horizontal length scale is larger than the first baroclinic Rossby radius of deformation for this region ( $\approx 10 \mathrm{~km}$ ), indicating an advective nature. The presence of warm eddies and meanders in this region agrees with the studies of Gouretski and Danilov (1993, 1994), and Schröder and Fahrbach (1999). The anticyclonic rotation can be 
explained by vorticity dynamics (Orsi et al., 1993).

The second core further south seems to be part of an advective pathway. It has slightly cooler temperatures and significantly lower oxygen levels than core 1 . Even though the upwelling isopycnals (due to wind forcing) towards the coast indicate eastward geostrophic motion, we are confident that the dominating ( $\mathrm{Ci}-$ sewski et al., 2010; Fahrbach et al., 1991) barotropic component is westward. Several studies at $30^{\circ} \mathrm{E}$ observed westward transport for the WDW density class (Park et al., 2001; Jullion et al., 2014) even though the baroclinic transport was to the east. Unfortunately, during ANT XX/2, the ship's Acoustic Doppler Current Profiler (ADCP) had to be switched off due to technical problems before the eastern section was occupied.

The biggest difference between the two cores was found in their ventilation signature, i.e. oxygen and CFC levels. At the eastern section measurements relevant for our analysis where only available between 400 and $600 \mathrm{~m}$, which is below the maximum temperature cores but within the maximum salinity. Hence, the measurements can be representative for the warm inflow. However, the $500 \mathrm{~m}$ contour line crosses several density lines so that the high values associated with core 1 and the warm eddy at $58^{\circ} \mathrm{S}$ are found at different densities. A comparison of profiles (Fig. 5) shows that the waters at $58^{\circ} \mathrm{S}$ originate from the cold regime while core 1 exhibits ACC characteristics. At $\gamma_{n} \approx 28.15 \mathrm{~kg} / \mathrm{m}^{3}$ the profiles overlap which means that the high CFC-12 value at $58^{\circ} \mathrm{S}$ could come from the same source as core 1 . High values at the SB along at a density of $\gamma_{n} \approx 28.1 \mathrm{~kg} / \mathrm{m}^{3}$ suggest that this area is a source region for the warm inflow. Several authors describe substantial water mass transformations at the SB in the Atlantic basin. Heywood and King (2002) show that significant interleaving of ACC and WG waters is seen particularly at intermediate depth, which inevitably leads to mixing of LCDW and WSDW. They also state that waters to the south of the Southern ACC Front (SACCF), which is situated between the SB and the PF, exhibit increased silicate and CFC concentrations, being consistent with our observations. Not only exchanges between the ACC and the WG but also exchanges with NADW coming from the north occur between the Drake Passage and the GM (Whitworth and Nowlin, 1987). Furthermore, vertical mixing occurs between UCDW and the rising LCDW at the SB (Orsi et al., 1995). These facts are able to explain the higher ventilation in this region.

Oxygen and CFC suggest lower values for core 2, which could indicate a different source for the southern branch of the warm inflow. Lower oxygen is found towards the centre of the ACC associated with UCDW. Core 2 exhibits an oxygen vs. neutral density profile similar to the station north of the SB (Fig. 5). Temperature and salinity suggest an origin at the SB for densities smaller than $28 \mathrm{~kg} / \mathrm{m}^{3}$, while denser water has its origin further north. However, mixing along the eastern boundary could alter the properties of the inflow significantly. Given the lack of CFC data at lower depth and measurements in general, it is difficult to draw a final conclusion regarding the origin of core 2 . Archambeau et al. (1998) show a CFC -12 section at $30^{\circ} \mathrm{E}$ from 44 to $69^{\circ} \mathrm{S}$. A band of high values between 0.2 and $0.5 \mathrm{pmol} / \mathrm{kg}$ follows the upwelling isopycnals associated with the warm inflow, which is located at roughly $500 \mathrm{~m}$ depth at the northern edge and rises up to $300 \mathrm{~m}$ at the southern edge. As we expect core 2 to represent the southern, advective path of the inflow which extends to $30^{\circ} \mathrm{E}$, this could mean that our measurements at $500 \mathrm{~m}$ depth are not in agreement with the actual values in the core, which could be higher.

How representative is the location of the two cores in our dataset regarding a general pattern of circulation? Indeed, several other sections located around $20^{\circ} \mathrm{E}$ show a warm core at about $60^{\circ} \mathrm{S}$ (Gouretski and Danilov, 1993; Huber et al., 1981), although the temperatures are just over $1{ }^{\circ} \mathrm{C}$. In the section analysed by Gouretski and Danilov (1993), core 1 is not so dominant in temperature but definitely seen in salinity. Furthermore, the section reveals a second core at $65^{\circ}$ S, coinciding with our core 2 . Also, the oxygen distribution is in agreement with the minimum being found in core 2 , having similar values to the oxygen minimum at the SB. Gouretski and Danilov (1993) applied a free inertial jet model (after Niiler and Robinson, 1967) in order to discuss possible mechanisms that control the pathway of the ACC. They concluded that the shape of the ACC in the study region is controlled by the bottom topography. Later, Park et al. (2001) applied the same model and state that the bottom topography can effectively hinder the eastward extension of the Weddell cold regime. In return, this means that the pathway for the warm inflow at the northern edge is controlled by a permanent topographic feature, hence leading to the regular occurrence of warm cores at e.g. $20^{\circ} \mathrm{E}, 60^{\circ} \mathrm{S}$. This is confirmed by the pattern of the standard deviation of the climatological temperature field (Fig. 9(b)) and the model results presented in this study. Even though the model is non-eddy resolving the barotropic stream function captures both modes, likely as a time-mean picture, as there is no observational evidence of a quasi-permanent flow forming the northern short route (Park et al., 2001). Nevertheless, the streamlines always go on a direct route through the location of core 1, except in 1962 . Based on the findings of the topographic influence of the ridge on the southward turn of the ACC, the significance of the stream function in that year is questionable, since all the other years show the turn of the streamlines at roughly the same position. The precise strength of the southward curl is given by the bottom velocities of the flow (Gouretski and Danilov, 1993; Park et al., 2001). The advective, southern branch, however, shows a higher seasonal and interannual variability in shape and strength. It is suggested that the strength of the southern limb is related to the regional wind field (Fahrbach et al., 2011). A low pressure system is centred at $65^{\circ} \mathrm{S}$ in the eastern part of the WG, thus leading to westerlies north and easterlies south of this latitude. Hence, the northern part of the warm inflow, which is eddy-driven, occurs against the wind, while obviously the advective part flows with the wind. During positive phases of the SAM, a southward shift of the westerly winds occurs, which according to Fahrbach et al. (2011) slows down the southern inflow path and reduces the warm inflow and vice versa. The variability at the eastern boundary in the barotropic stream function of BRIOS seems to be related to the SAM index, which exhibits a trend to a more positive phase since the 1960s. Until the 1980 s, the index was predominantly negative and we can see a stronger southern branch in the stream function which exceeds further to the east. On the other hand, the limb has been very week since the beginning of the 2000s, and was accompanied by an almost exclusively positive SAM. This relation will ultimately lead to variability of the WDW further downstream, which was pointed out by Fahrbach et al. (2011). Nevertheless, we have shown that the inflow at the eastern boundary is not trivial and that there is the possibility of different origins of the warm water. By the time it reaches the GM, significant cooling and mixing with cold regime waters has occurred as the OMP results show. Also, the lighter CDW (UCDW) has been entrained into the surface mixed layer, a process which is necessary to compensate for the heat loss at the surface (Park et al., 2001). The WDW at the GM shows uniform properties, which is why we believe that the inflow water has mixed between 0 and $30^{\circ} \mathrm{E}$. A meridional temperature section at $10^{\circ} \mathrm{E}$ (Huber et al., 1981) shows only one large patch of warm water just before Maud Rise is reached, where the warm water will split again. Although, the SAM seems to be able to cause variations in the warm inflow, it has to be kept in mind that the WDW which is measured at the GM is already altered significantly compared to the direct inflow. Different mixing ratios between the cold and warm regime and also between CDW from different origins could lead to variability of WDW further downstream. Also, 
the cold regime seems to be more pronounced in some years than others (Schröder and Fahrbach, 1999), which provides more or less cool water for mixing at the eastern boundary.

\section{Summary}

Hydrographic data at the eastern boundary of the WG reveal two maximum temperature cores around $20^{\circ} \mathrm{E}$. The first core is located at the northern edge of the warm inflow $\left(60^{\circ} \mathrm{S}\right)$ with a peak in CFC-12 and elevated oxygen. It has been identified as an anticyclonic eddy carrying ACC waters from the SB into the WG, which agrees with findings of previous literature. The combined analysis of model results and climatological temperature fields support the regular occurrence of warm cores at this location, which form a short inflow path set up by eddy-mixing. The second core $\left(66^{\circ} \mathrm{S}\right)$ is slightly cooler and has minimum oxygen and CFC-12 values, although the latter were measured below the maximum temperature core and could be higher above this depth. This core represents an advective pathway which extends beyond $30^{\circ} \mathrm{E}$ before turning westward to form the southern limb of the warm inflow. The origin of this water could lay just north of the SB within the ACC, where the UCDW forms an oxygen minimum, thus explaining the lower ventilation of the southern inflow. The competing effects of topography and the Coriolis force during conservation of potential vorticity determine the shape of the two pathways. Model results exhibit a considerable variability of the southern, advective branch which can be connected to changes in the local wind field, determined by the SAM. Different mixing ratios between cold regimes waters and CDW with different origins can lead to significant temporal variability of the WDW measured downstream at the GM, which has to be considered when analysing trends in water mass properties. The area remains an undersampled region. The dynamical connection between $20^{\circ} \mathrm{E}$ and the GM is still not fully understood. More observations are needed in order to gain more insight on this subject, which then could be combined with a more detailed model analysis if possible. To investigate the source regions of the warm inflow within the ACC one could release numerical floats at the eastern boundary in the model and plot trajectories backward in time. Trajectories calculated forward in time could help understanding the pathways from the boundary towards the west.

\section{Acknowledgements}

We would like to express our gratitude to the officers and crew of $R V$ Polarstern for their efficient assistance during the ANT $\mathrm{XX} / 2$ cruise. We thank the scientific party for excellent cooperation. Special thanks to A. Wisotzki for the outstanding care with the data sampling, for processing the oceanographic data (http://dx. doi.org/10.1594/PANGAEA.738486). Thanks to Klaus Bulsiewicz for measuring the CFC samples. The expedition ANT XX/2 was financed by Polarstern grant no. PS63. Thank you to H.H. Hellmer and three anonymous reviewers for their detailed and constructive comments, which helped to improve the manuscript significantly.

\section{References}

Archambeau, A.-S., Pierre, C., Poisson, A., Schauer, B., 1998. Distributions of oxygen and carbon stable isotopes and CFC-12 in the water masses of the Southern Ocean at $30^{\circ} \mathrm{E}$ from South Africa to Antarctica: results of the CIVA 1 cruise. J. Mar. Syst. 17, 25-38.

Bakker, D., Hoppema, M., Schröder, M., 2008. A rapid transition from ice covered $\mathrm{CO}_{2}$-rich water to a biologically mediated $\mathrm{CO}_{2}$ sink in the eastern Weddell Gyre. Biogeosciences 5, 1373-1386.
Beckmann, A., Timmermann, R., Pereira, A.F., Mohn, C., 2001. The effect of flow at Maud Rise on the sea-ice cover-numerical experiments. Ocean Dyn. 52 (1), 0011-0025.

Carmack, E., 1977. Water mass characteristics of the Southern Ocean south of the Polar Front. In: Angel, M. (Ed.), A voyage of discovery, George Deacon 70th Anniversary Volume. Pergamon, New York, pp. 15-41.

Cisewski, B., Strass, V., Leach, H., 2010. Circulation and transport of water masses in the Lazarev Sea, Antarctica, during summer and winter 2006. Deep-Sea Res. I 58, 186-199.

Deacon, G., 1937. The hydrology of the Southern Ocean. Discov. Rep. 15, 1-24. Deacon, G., 1979. The Weddell Gyre. Deep-Sea Res. 26A, 981-995.

Fahrbach, E., Hoppema, M., Rohardt, G., Boebel, O., Klatt, O., Wisotzki, A., 2011. Warming of deep and abyssal water masses along the Greenwich meridian on decadal time scales: the Weddell Gyre as a heat buffer. Deep-Sea Res. II (58), 2509-2523.

Fahrbach, E., Knoche, M., Rohardt, G., 1991. An estimate of water mass transformation in the southern Weddell Sea. Mar. Chem. 35, 25-44.

Fütterer, D., Kattner, G., 2005. The expedition ANTARKTIS-XX of RV Polarstern in 2002/2003. Ber. Polarforschung 495.

Gordon, A.L. Huber, B.A., 1984. Thermohaline stratification below the Southern Ocean sea ice. J. Geophys. Res. 89 (C1), 641-648.

Gouretski, V.V., Danilov, A.I., 1993. Weddell Gyre: structure of the eastern boundary. Deep-Sea Res. 40 (3), 561-582.

Gouretski, V.V., Danilov, A.I., 1994. Characteristics of warm rings in the African sector of the Antarctic Circumpolar Current. Deep-Sea Res. I 41 (8), 1131-1157.

Heywood, K.J., King, B.A., 2002. Water masses and baroclinic transport in the South Atlantic and Southern Oceans. J. Mar. Res. 60 (5), 639-676.

Huber, B., Rennie, S., Georgi, D., Jacobs, S., Gordon, A., 1981. Ara Islas Orcadas Data Report, Cruise 12, Ref. CU-2-81-TR2. Technical report, Lamont-Doherty Geol. Observ., Palisades, New York.

Huhn, O., Hellmer, H.H., Rhein, M., Rodehacke, C., Roether, W., Schodlok, M.P., Schröder, M., 2008. Evidence of deep- and bottom- water formation in the western Weddell Sea. Deep-Sea Res. II (55), 1098-1116.

Huhn, O., Rhein, M., Hoppema, M., van Heuven, S., 2013. Decline of deep and bottom water ventilation and slowing down of anthropogenic carbon storage in the Weddell Sea, 1984-2011. Deep-Sea Res. I 76, 66-84.

Johnson, G.C., 2008. Quantifying Antarctic Bottom Water and North Atlantic Deep Water volumes. J. Geophys. Res. 113 (C05027).

Jullion, L., Garabato, A.C.N., Bacon, S., Meredith, M.P., Brown, P.J., Torres-Valdés, S., Speer, K.G., Holland, P.R., Dong, J., Bakker, D., Hoppema, M., Loose, B., Hugh J. Venables, W.J.J., Messias, M.-J., Fahrbach, E., 2014. The contribution of the Weddell Gyre to the lower limb of the Global Overturning Circulation. J. Geophys. Res. Oceans 119, 3357-3377.

Klatt, O., Fahrbach, E., Hoppema, M., Rohardt, G., 2005. The transport of the Weddel Gyre across the Prime Meridian. Deep-Sea Res. Part II: Top. Stud. Oceanogr. 52 (3-4), 513-528.

Larque, L., Maamaatuaiahutapu, K., Garcon, V., 1997. On the intermediate and deep water flow in the South Atlantic Ocean. J. Geophys. Res. 102 (C6), 12425-12440. Meredith, M., 2013. Replenishing the abyss. Nat. Geosci. 6, 166-167.

Naveira Garabato, A., Mc Donagh, E., Stevens, D., Heywood, K., Sanders, R., 2002. On the export of Antarctic Bottom Water from the Weddell Sea. Deep-Sea Res. Part II $49,4715-4742$.

Nicholls, K.W., Osterhus, S., Makinson, K., Gammelsrod, T., Fahrbach, E., 2009. Iceocean processes over the continental shelf of the southern Weddell Sea, Antarctica: a review. Rev. Geophys. 47 (RG3003).

Niiler, P., Robinson, A., 1967. The theory of free inertial jets. Tellus 19 (4), 601-619.

Orsi, A., Johnson, G., Bullister, J., 1999. Circulation, mixing, and production of Antarctic Bottom Water. Prog. Oceanogr. 43, 55-109.

Orsi, A., Whitworth, T., Nowlin Jr., W., 1995. On the meridional extent and fronts of the Antarctic Circumpolar Current. Deep-Sea Res. 34, 641-673.

Orsi, A.H., Nowlin Jr., W.D., Whitworth, T., 1993. On the circulation and stratification of the Weddell Gyre. Deep-Sea Res. 40 (1), 169-203.

Palmer, M., Gomis, D., del Mar Flexas, M., Jullion, L., Tsubouchi, T., NaveiraGarabato, A., 2012. Water mass pathways and transport over the Scotia Ridge west of $50^{\circ}$ W. Deep-Sea Res. Part I 59, 8-24.

Park, Y.-H., Charriaud, E., Craneguy, P., 2001. Fronts, transport, and Weddell Gyre at 30E between Africa and Antarctica. J. Geophys. Res. 106 (2), 2857-2879.

Patterson, S., Whitworth, T., 1990. Physical oceanography. In: Antarctic Sector of the Pacific. Elsevier, New York, pp. 55-93.

Reid, J., Nowlin Jr., W.D., Patzert, W., 1977. On the characteristics and circulation o the southwestern Atlantic Ocean. J. Phys. Oceanogr. 7, 62-91.

Saunders, P., King, B., 1995. Ocean fluxes on the WOCE A11 section. J. Phys. Oceanogr. 25 (9), 1942-1958.

Schröder, M., Fahrbach, E., 1999. On the structure and the transport of the eastern Weddell Gyre. Deep-Sea Res. II 46, 501-527.

Schröder, M., Wisotzki, A., 2010. Physical Oceanography During POLARSTERN cruise ANT-XX/2. Technical Report, Alfred Wegener Institute, Helmholtz Centre for Polar and Marine Research, Bremerhaven.

Smedsrud, L.H., 2005. Warming of the deep water in the Weddell Sea along the Greenwich meridian: 1977-2001. Deep-Sea Res. I (52), 241-258.

Timmermann, R., Beckmann, A., Hellmer, H.H., 2002. Simulations of ice-ocean dynamics in the Weddell Sea 1 . Model configuration and validation. J. Geophys. Res. 107 (C3) 10-1-11.

Tomczak, M., 1981. A multiparameter extension of temperature/salinity diagram techniques for the analysis of non-isopycnal mixing. Prog. Oceanogr. 10 $147-171$.

Tomczak, M., Large, D.G., 1989. Optimum multiparameter analysis of mixing in the thermocline of the Eastern Indian Ocean. J. Geophys. Res. 94 (C11), 16141-16149.

van Caspel, M., Schröder, M., Huhn, O., Hellmer, H., 2015. Precursors of Antarctic 
Bottom Water formed on the continental shelf off Larsen Ice Shelf. Deep-Sea Res. Part I 99, 1-9.

Vanicek, M., Siedler, G., 2002. Zonal fluxes in the deep layers of the Western South
Atlantic Ocean. J. Phys. Oceanogr. 32 (8), 2205-2235.

Whitworth, T., Nowlin, W., 1987. Water masses and currents of the Southern Ocean at the Greenwich Meridian. J. Geophys. Res. 92 (C6), 6462-6476. 